\title{
Convenient Reagent for the Copper-Catalyzed Asymmetric Methyl 1,4-Addition Reaction
}

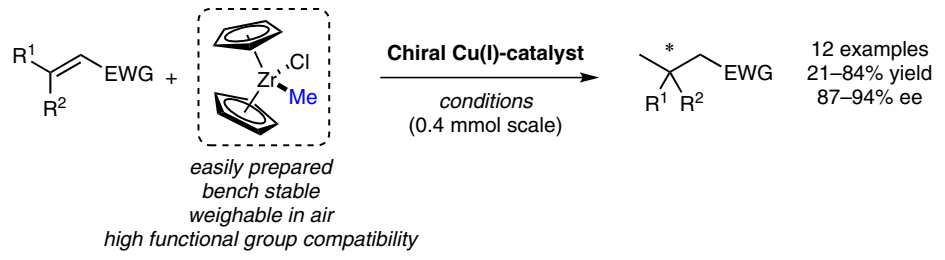

\section{1,4-conjugate} addition

\section{stable zirconium} reagent

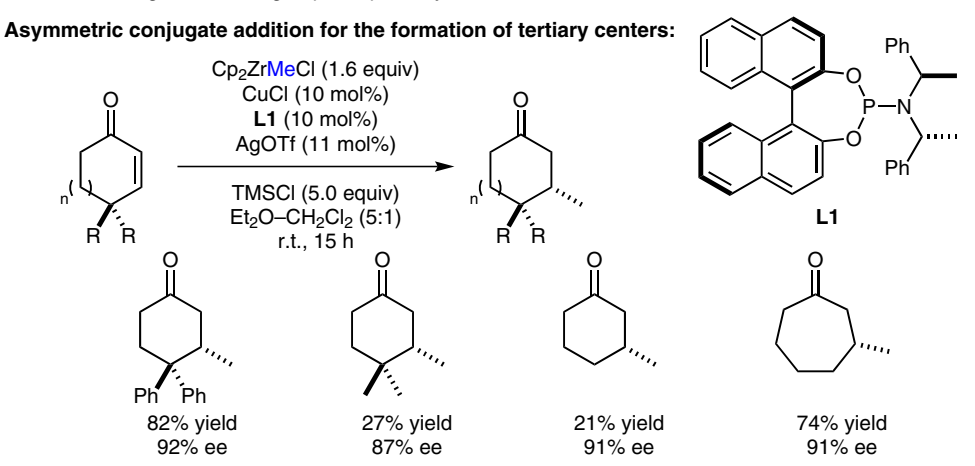

Asymmetric conjugate addition for the formation of quaternary centers:

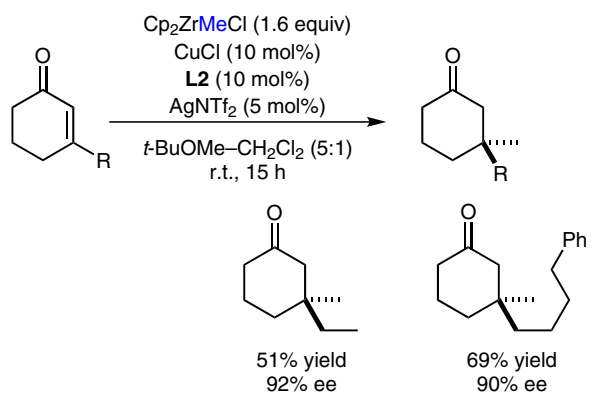<smiles></smiles>

Significance: Tertiary and quaternary stereocenters bearing a methyl group are common structural units in a wide array of natural products and pharmaceuticals. The synthesis of such compounds is usually performed by the asymmetric conjugate methyl addition to $\alpha, \beta$-unsaturated carbonyl compounds. Unfortunately, this approach usually relies on the use of impractical reagents (e.g. pyrophoric reagents, low functional group compatibility). In this work, the authors disclosed the use of $\mathrm{Cp}_{2} \mathrm{ZrMeCl}$ as an efficient and operationally friendly reagent in copper-catalyzed methyl 1,4-addition reactions.
Comment: The use of $\mathrm{Cp}_{2} \mathrm{ZrMeCl}$ as a methyl source in combination with a chiral copper catalyst allowed the formation of $\beta$ - and $\delta$-tertiary and quaternary centers in generally good yields and excellent enantioselectivities. The reaction was applied to a variety of cyclic and acyclic carbonyl compounds, allyl chlorides and in the synthesis of $(R)-(-)$-muscone. The zirconium reagent was prepared on a $10 \mathrm{~g}$ scale reaction from $\mathrm{Cp}_{2} \mathrm{ZrCl}_{2}$ and was demonstrated to be stable for up to six months when stored under inert gas at room temperature.

SYNFACTS Contributors: Mark Lautens, Ivan Franzoni 